\title{
Serious Mental Illness in Primary Care: a National Physician Survey
}

J Gen Intern Med 36(3):833-5

DOI: $10.1007 / \mathrm{s} 11606-020-05950-8$

(C) Society of General Internal Medicine 2020

$\mathrm{P}$ eople with serious mental illnesses (SMIs) like schizophrenia have 2-3 times greater mortality than the overall population due to high rates of poorly controlled medical conditions including cardiovascular disease. ${ }^{1}$ Evidence shows sub-optimal care of medical conditions among many people with SMI. ${ }^{2}$ Primary care physicians have an important role to play in improving receipt of guidelineconcordant physical healthcare for people with SMI. ${ }^{3}$ But little is known about PCPs' views on caring for patients with SMI.

\section{METHODS}

We surveyed a nationally representative sample of 1000 US physicians identifying as family, internal, or general medicine practitioners using a tailored Dillman method. ${ }^{4}$ A simple random sample of physicians selected from the American Medical Association (AMA) Masterfile were mailed a questionnaire, \$2 incentive, and postage-paid return envelope in February 2019. Non-respondents received identical packets in March, April, June, July, and August 2019. Eligible physicians were those in the original $N=1000$ sample definitively identified as practicing primary care at the address on file for the entire field period. The instrument (Appendix in the Electronic Supplementary Material [ESM]) was developed by the study team. The four survey domains are italicized in Table 2 (see Table 2 and Appendix (ESM) for item wording/ responses).

The response rate was 54\% (361 returned surveys from 668 eligible physicians). Eligible physicians represented 50 states and responding physicians represented 49 states (WY absent). Twenty-five surveys with $>50 \%$ missing data were excluded

Electronic supplementary material The online version of this article (https://doi.org/10.1007/s11606-020-05950-8) contains supplementary material, which is available to authorized users.

Received February 2, 2020

Accepted May 29, 2020

Published online June 10, 2020 from analyses. Response did not differ by specialty, age, sex, degree (MD/DO), or practice type. Chi-squared tests showed that more non-responders $(37.2 \%)$ than responders $(22.1 \%)$ were from the south; analyses incorporated weights adjusting for this difference. Data were analyzed descriptively. We used chi-squared tests to compare responses among physicians with versus without onsite mental health and care coordination services. This study was deemed exempt from review by the JHSPH Institutional Review Board.

\section{RESULTS}

Respondents' demographic characteristics were similar to PCPs nationally (Table 1). Over $40 \%$ of practices did not perform population health tracking or care coordination; one-third had onsite mental healthcare. Fifty-two percent of PCPs thought that people with SMI want to change their health behaviors (Table 2). More than three-quarters reported ability to treat physical and mental health symptoms in SMI, but only $40.9 \%$ reported ability to treat substance use. Over $70 \%$ endorsed joint responsibility with specialty mental health providers for caring for people with SMI. Physicians at clinics with onsite mental health services reported greater ability to provide smoking cessation, mental health, and weight management services $(p<0.05$; Appendix Table 1 in the ESM). Physicians at clinics with care coordination services were more likely to report need for a health educator and nurse to support care coordination and enhanced reimbursement $(p<0.05$; Appendix Table 2 in the ESM).

\section{DISCUSSION}

The majority of US PCP respondents endorsed joint responsibility for caring for patients with SMI alongside specialty mental health providers, but the population health management and care coordination functions needed for integrated care $^{5}$ were absent from more than $40 \%$ of practices. Only $52 \%$ of respondents believed that people with SMI wanted to make health behavior change, an attitude at odds with evidence showing people with SMI's desire and ability to lose weight and quit smoking. ${ }^{6}$ Only $41 \%$ of PCPs reported that they were able to treat substance use, suggesting a need to bolster capacity to treat this common co-occurring issue in SMI. PCPs with onsite mental health services reported greater ability to deliver 
Table 1 Characteristics of Primary Care Physician Survey Respondents, $2019(N=336)$

\begin{tabular}{|c|c|c|}
\hline & $\begin{array}{l}\text { Survey } \\
\text { respondents }\end{array}$ & $\begin{array}{l}\text { National primary } \\
\text { care physician } \\
\text { population }^{1}\end{array}$ \\
\hline \multicolumn{3}{|l|}{ Specialty } \\
\hline Family practice & $52.4 \%$ & $51.5 \%$ \\
\hline Internal medicine & $43.2 \%$ & $44.9 \%$ \\
\hline General practice & $4.5 \%$ & $3.6 \%$ \\
\hline \multicolumn{3}{|l|}{ Age } \\
\hline$<35$ & $7.6 \%$ & $5.7 \%$ \\
\hline $35-44$ & $19.1 \%$ & $22.6 \%$ \\
\hline $45-54$ & $29.4 \%$ & $30.7 \%$ \\
\hline $55-64$ & $28.5 \%$ & $27.3 \%$ \\
\hline $65+$ & $15.5 \%$ & $13.7 \%$ \\
\hline \multicolumn{3}{|l|}{ Sex } \\
\hline Male & $58.8 \%$ & $60.9 \%$ \\
\hline Female & $41.2 \%$ & $39.1 \%$ \\
\hline \multicolumn{3}{|l|}{ Region } \\
\hline South & $29.8 \%$ & $35.6 \%$ \\
\hline West & $26.1 \%$ & $24.6 \%$ \\
\hline Midwest & $22.1 \%$ & $20.9 \%$ \\
\hline Northeast & $22.1 \%$ & $19.0 \%$ \\
\hline \multicolumn{3}{|l|}{ Practice type $^{2}$} \\
\hline Group practice & $50.9 \%$ & Data not available \\
\hline $\begin{array}{l}\text { Solo or two-physician } \\
\text { practice }\end{array}$ & $17.5 \%$ & Data not available \\
\hline Government-based practice & $11.4 \%$ & Data not available \\
\hline Non-governmental hospital & $4.6 \%$ & Data not available \\
\hline Other ${ }^{3}$ & $15.6 \%$ & Data not available \\
\hline \multicolumn{3}{|c|}{ Percent of patient panel with bipolar disorder or schizophrenia } \\
\hline $0-10 \%$ & $79.1 \%$ & Data not available \\
\hline $10-20 \%$ & $17.6 \%$ & Data not available \\
\hline $30-40 \%$ & $2.7 \%$ & Data not available \\
\hline $40+\%$ & $0.6 \%$ & Data not available \\
\hline \multicolumn{3}{|c|}{ Services provided at physician's practice } \\
\hline $\begin{array}{l}\text { Weight management or } \\
\text { dietary counseling }\end{array}$ & $81.2 \%$ & Data not available \\
\hline Diabetes education & $79.1 \%$ & Data not available \\
\hline $\begin{array}{l}\text { Tobacco smoking cessation } \\
\text { treatment }\end{array}$ & $77.3 \%$ & Data not available \\
\hline $\begin{array}{l}\text { Population health tracking } \\
\text { of chronic disease metrics } \\
\text { (e.g., HBA1c, flu shots) in } \\
\text { the practice's patient panel }\end{array}$ & $58.0 \%$ & Data not available \\
\hline $\begin{array}{l}\text { Care coordination for high- } \\
\text { need patients }\end{array}$ & $57.4 \%$ & Data not available \\
\hline $\begin{array}{l}\text { Onsite mental health } \\
\text { treatment services }\end{array}$ & $31.8 \%$ & Data not available \\
\hline $\begin{array}{l}\text { Onsite substance use } \\
\text { treatment services }\end{array}$ & $19.0 \%$ & Data not available \\
\hline $\begin{array}{l}\text { An online patient portal } \\
\text { where patients can log-in to } \\
\text { see appointments, lab results, } \\
\text { etc. }\end{array}$ & $8.2 \%$ & Data not available \\
\hline $\begin{array}{l}\text { My practice does not } \\
\text { provide any of these services } \\
\text { for any patients }\end{array}$ & $5.3 \%$ & Data not available \\
\hline
\end{tabular}

${ }^{1}$ Petterson S, McNellis R, Klink K, Meyers D, Bazemore A. The State of Primary Care in the United States: A Chartbook of Facts and Statistics. January 2018

${ }^{2}$ National data on practice type among primary care physicians defined as family, internal, and general medicine physicians is not available ${ }^{3}$ Includes the following: other-patient care; locum tenens; no classification

services (mental health, smoking cessation, and weight management) involving counseling. PCPs with onsite care coordination reported a higher need for additional coordination supports, perhaps suggesting that practices with care coordination serve high-need patient populations and/or recognition of the value of care coordination.
Table 2 US Primary Care Physicians' Views Regarding Care for Patients with Serious Mental Illness $(N=336)$

\begin{tabular}{|c|c|}
\hline & $\%(95 \% \mathrm{CI})$ \\
\hline \multicolumn{2}{|c|}{ Premature mortality and health behavior change in SMI (\% agree $)^{1}$} \\
\hline $\begin{array}{l}\text { People with SMI are more likely to die } \\
\text { prematurely from medical conditions than } \\
\text { psychiatric causes. }\end{array}$ & $76.0 \%(71.0-80.3$ \\
\hline $\begin{array}{l}\text { People with SMI can make health behavior } \\
\text { change. }\end{array}$ & $74.3 \%(69.3-78.7$ \\
\hline $\begin{array}{l}\text { People with SMI want to make health behavior } \\
\text { change. }\end{array}$ & $52.1 \%(46.6-57.4$ \\
\hline $\begin{array}{l}\text { Ability to care for patients with SMI }(\% \text { able })^{2} \\
\text { How would you rate your ability to: }\end{array}$ & \\
\hline $\begin{array}{l}\text { Treat chronic physical health conditions (e.g., } \\
\text { diabetes mellitus) experienced by people with } \\
\text { SMI? }\end{array}$ & $93.8 \%(90.6-95$. \\
\hline & 90.7 \\
\hline to people & $79.8 \%$ \\
\hline $\begin{array}{l}\text { Treat mental health symptoms experienced by } \\
\text { cople with SMI? }\end{array}$ & $78.2 \%(73.4-82$ \\
\hline $\begin{array}{l}\text { Provide weight management counseling to } \\
\text { ople with SMI? }\end{array}$ & $77.3 \%(72.4-81$. \\
\hline Treat substance use issues experience & 4 \\
\hline
\end{tabular}
people with SMI?

Responsibility for treating patients with $\mathrm{SMI}^{3}$

Who should have primary responsibility for treating physical health conditions among people with SMI?
Primary care physicians
Specialty mental health providers
$22.6 \%(18.4-27.5)$
$6.6 \%(4.3-9.8)$

Joint responsibility

$70.8 \%(65.6-75.5)$

Who should have primary responsibility for addressing tobacco smoking among people with SMI?
Primary care physicians
$22.9 \%(18.6-27.7)$
Specialty mental health providers
Joint responsibility
$5.7 \%(3.7-8.8)$
$71.4 \%(66.3-76.1)$

Who should have primary responsibility for addressing healthy diet and exercise among people with SMI?
Primary care physicians
$26.7 \%(22.1-31.7)$
Specialty mental health providers
$1.2 \%(0.5-3.3)$
Joint responsibility
$72.1 \%(70.0-76.7)$

Resources to support care for patients with $S M I^{4}$

Are there resources that would help you to provide primary care more effectively to people with SMI?

A health educator trained in working with people with SMI to provide behavioral counseling related to chronic medical conditions

(e.g., diabetes education, smoking cessation)

A nurse to provide care coordination for

patients with SMI (e.g., making appointments, lab

follow-up)

A higher-than-typical reimbursement rate for providing primary care to people with SMI

Training on how to effectively communicate with patients with SMI

A lay caregiver to accompany patients with

SMI to primary care appointments

A nurse to accompany patients with SMI to primary care appointments

None of these resources would help me provide primary care to patients with SMI

$68.6 \%(63.4-73.4)$

$63.2 \%(57.8-68.2)$

$47.9 \%(42.5-53.3)$

$44.5 \%(39.2-49.9)$

$43.9 \%(38.6-49.3)$

$30.8 \%(26.1-36.0)$

$8.2 \%(5.6-11.7)$

${ }^{1}$ Premature mortality and health behavior change in SMI items: Response options included strongly agree, somewhat agree, agreel disagree, somewhat disagree, and strongly disagree. "Strongly agree" and "Somewhat agree" were combined to indicate \% agree

${ }^{2}$ Ability to care for patients with SMI items: Response options included entirely unable, mostly unable, somewhat able, and very able. "Somewhat able" and "Very able" were combined to indicate \% able

${ }^{3}$ Responsibility for treating patients with SMI items: Respondents were asked to choose one option: "primary care physicians," "specialty mental health providers," or "joint responsibility" ${ }^{4}$ Resources to support care for patients with SMI items: Respondents were asked to select all that apply from the resources listed 
About one-third $(N=332)$ of physicians in the original sample had an incorrect practice status, specialty, or address and were deemed ineligible. While our sample was fairly small, with eligible physicians representing all 50 states but only 660 of 47,701 zip codes, respondents' characteristics were similar to those of PCPs nationally. Our survey did not assess whether PCPs' views on needed resources differed for SMI versus other chronic conditions.

A national sample of US PCPs viewed specialty mental healthcare providers and PCPs as jointly responsible for the health of people with SMI; financing and delivery models that effectively support such shared responsibility are needed.

Emma E. McGinty, PhD, $\mathrm{MS}^{1}$

Elizabeth $M$. Stone, $\mathrm{MS}^{1}$

Gail L. Daumit, $M D, M H S^{2}$

${ }^{1}$ Department of Health Policy and Management, Johns Hopkins Bloomberg School of Public Health

Baltimore, MD, USA

${ }^{2}$ Division of General Internal Medicine, Johns Hopkins School of Medicine,

Baltimore, MD, USA

Corresponding Author: Emma E. McGinty, PhD, MS; Department of Health Policy and Management, Johns Hopkins Bloomberg School of Public Health Baltimore, MD, USA (e-mail: bmcginty@jhu.edu).
Funding Information Dr. McGinty received support from NIMH grant K01MH106631.

\section{Compliance with Ethical Standards:}

This study was deemed exempt from review by the JHSPH Institutional Review Board.

Conflict of Interest: The authors declare that they do not have a conflict of interest.

\section{REFERENCES}

1. Olfson M, Gerhard T, Huang C, Crystal S, Stroup TS. Premature mortality among adults with schizophrenia in the United States. JAMA Psychiat. 2015;72(12):1172-81.

2. McGinty EE, Baller J, Azrin ST, Juliano-Bult D, Daumit GL. Quality of medical care for persons with serious mental illness: A comprehensive review. Schizophr Res. 2015;165(2-3):227-35.

3. Bao Y, Casalino LP, Pincus HA. Behavioral health and health care reform models: patient centered medical home, health home, and accountable care organization. J Behav Health Serv Res. 2013;40:121-32.

4. Dillman DA, Smyth JD, Christian LM. Internet, phone, mail, and mixedmode surveys: the tailored design method. John Wiley \& Sons; 2014.

5. Murphy KA, Daumit GL, Stone EM, McGinty EE. Physical Health Outcomes and Implementation of Behavioral Health Homes: A Comprehensive Review. Int Rev Psychiatry. 2019; In Press.

6. McGinty EE, Baller J, Azrin ST, Juliano-Bult D, Daumit GL. Interventions to address medical conditions and health-risk behaviors among persons with serious mental illness: a comprehensive review. Schizophr Bull. 2015;42(1):96-124.

Publisher's Note: Springer Nature remains neutral with regard to jurisdictional claims in published maps and institutional affiliations. 